\title{
Six-Hour Sepsis Bundle Decreases Mortality: Truth or Illusion - A Prospective Observational Study
}

\author{
Pooja Anthwal, Nirmal Kumar, Ayush Manchanda, Bhawna Garg \\ Department of Pediatrics, St. Stephen's Hospital, Delhi, India
}

\section{Abstract}

\begin{abstract}
Aim: The aim of the study is to evaluate whether 6-h sepsis bundle component compliance (complete vs. incomplete) decreases mortality in pediatric patients with severe sepsis and septic shock. Methodology: The study was conducted at a tertiary care hospital. Patients aged 1 month-13 years admitted to pediatric intensive care unit with severe sepsis, or septic shock were prospectively enrolled. The clinical data and blood investigations required for sepsis bundle were recorded. Predicted mortality was calculated at admission by the online pediatric index of mortality-2 (PIM-2) score calculator. Patients who fulfilled all the components of 6-h sepsis bundle were taken as compliant while failure to fulfill even a single component rendered them noncompliant. The outcome was recorded as died or discharged. Results: Of 116 patients, $90(77.59 \%)$ had $100 \%$ sepsis bundle component compliance and were taken into the compliant group while the rest $26(22.41 \%)$ were noncompliant. Forty out of 90 patients (44.4\%) died in compliant group in comparison to 5 out of $26(19.3 \%)$ in noncompliant group, $P=0.020$. The pre- and post-interventional lactates were significantly higher in compliant group as compared to the noncompliant group, $P<0.0001$ and 0.019 , respectively. Rising lactate level parallels increasing predicted mortality by PIM-2 score in compliant group, but this association failed to reach significance in noncompliant group which can be attributed to less number of subjects available in this group. Conclusion: Irrespective of sepsis bundle compliance (complete/incomplete), outcome depends on the severity of illness reflected by high lactate and predicted mortality.
\end{abstract}

Keywords: Lactate clearance, mortality, pediatric index of mortality-2 score, sepsis bundle, septic shock

\section{INTRODUCTION}

Sepsis is a systemic, deleterious host response to infection leading to severe sepsis and septic shock. Severe sepsis and septic shock are major health-care problems, affecting millions of people around the world each year, killing one in four (and often more), and increasing in incidence. ${ }^{[1-5]}$ According to the World Health Organization estimates, sepsis accounts for $60 \%-80 \%$ of lost lives per year in childhood. ${ }^{[6]}$ Similar to polytrauma, acute myocardial infarction or stroke, the speed and appropriateness of therapy administered in the initial hours after severe sepsis develops are likely to influence outcome.

The recommendations of surviving sepsis campaign (SSC) guidelines are intended to provide guidance for the clinician caring for a patient with severe sepsis or septic shock. The outcome improvement can be made through education and process change by SSC guidelines for those caring for severe sepsis patients in the intensive care unit (ICU) and non-ICU settings across the spectrum of acute care. ${ }^{[7]}$

\begin{tabular}{|l|l|}
\hline \multicolumn{3}{|c|}{ Access this article online } \\
\hline Quick Response Code: & Website: \\
\hline & www.ijccm.org \\
\cline { 2 - 2 } & \\
\hline
\end{tabular}

In 2004, the SSC endorsed the early goal-directed therapy for the management of severe sepsis and septic shock. It was aimed at obtaining a $25 \%$ reduction in mortality over the following 5 years in patients with septic shock worldwide. ${ }^{[8,9]}$ These guidelines have been summarized by the SSC in sepsis bundles, which represent key elements of care regarding the diagnosis and treatment of patients with septic shock. ${ }^{[10]}$

The Institute for the SSC provides in 2004 two bundles for septic shock patients: The 6-h resuscitation bundle and the 24-h management bundle (http://www.ihi.org/IHI/Topics/ CriticalCare/Sepsis). Many studies showed that implementation of 6-h resuscitation and 24-h management sepsis bundles decreased crude in-hospital or day 28 mortality, reduced the length of stay (in hospital/ICU), reduced the cost of care and

Address for correspondence: Dr. Pooja Anthwal, Department of Pediatrics, St. Stephen's Hospital, Delhi - 110 054, India. E-mail: poojaanthwal2010@gmail.com

This is an open access journal, and articles are distributed under the terms of the Creative Commons Attribution-NonCommercial-ShareAlike 4.0 License, which allows others to remix, tweak, and build upon the work non-commercially, as long as appropriate credit is given and the new creations are licensed under the identical terms.

For reprints contact: reprints@medknow.com

How to cite this article: Anthwal P, Kumar N, Manchanda A, Garg B. Six-hour sepsis bundle decreases mortality: Truth or illusion-A prospective observational study. Indian J Crit Care Med 2018;22:852-7. 
improved the patients' quality of life..$^{[11-14]}$ The beneficial effect of sepsis bundles on mortality has been confirmed in a meta-analysis, including 50 studies published from 2004 to 2014 showing a significant decrease in mortality in the majority of studies with an overall odds ratio of 0.66 (95\% confidence interval: $0.61-0.72) .{ }^{[15]}$

Several studies also showed that the extent of the decrease in mortality could depend on the number of bundle interventions completed. ${ }^{[12,13,16,17]}$

Over the last 10 years or so, the epidemiology of pediatric severe sepsis has been dramatically affected by the introduction of effective vaccines against what were the most common causes of community-acquired sepsis in children.

It is becoming increasingly common that patients admitted to pediatric intensive care with severe sepsis in this current postvaccine era are those with extreme prematurity, preexisting comorbidities, or who are immunocompromised in some way. $^{[18]}$

Due to this change in epidemiology, understanding the pathophysiology of pediatric sepsis has proven more difficult, and rational interventions to interrupt the "sepsis cascade" have proven less effective than predicted, probably because these children are not previously healthy with community-acquired sepsis, but are a heterogeneous mixture of patients with varied pathologies. It is likely that more generic measures or "bundles of care," such as are recommended in tools such as the SSC, will prove beneficial in pediatric practice, as they have been shown to be in adult practice. ${ }^{[7]}$

The 6-h sepsis resuscitation bundle in many studies has been associated with decreased mortality in patients of severe sepsis and septic shock. However, the application of these guidelines for the management of severe sepsis and septic shock in pediatric patients is still poor with little data available from studies on pediatric population in India. Very few studies have been done so far to assess the impact of 6-h sepsis bundle on the outcome of pediatric patients with severe sepsis and septic shock world over including India till now.

\section{Aim and Objective}

The aims and objectives of the study are to evaluate whether 6-h sepsis bundle component compliance (complete vs. incomplete) makes any significant difference to the outcome in pediatric patients with severe sepsis and septic shock. The outcome being measured in terms of mortality and surrogates of the severity of illness.

\section{Methodology}

The study was conducted in a tertiary care hospital in Delhi between May 2015 and June 2017. It was a prospective observational study. Patients from 1 month to 13 years of age (excluding neonates) with severe sepsis and septic shock were included in the study. Prior approval was obtained from hospital's Research Ethics Committee. Informed consent from the parents of eligible children was obtained. Patient's age, sex, admission date, vitals, fluid resuscitation, time of antibiotics given, maximum dose and duration of inotropes, lactate levels at admission and after $6 \mathrm{~h}$, blood cultures, and blood gas were recorded after admission and compliance to each of the components of $6 \mathrm{~h}$ sepsis bundle was documented in a predesigned pro forma. Variables required for calculating predicted mortality were recorded at admission and entered into an online pediatric index of mortality-2 (PIM-2) score calculator which gives the likelihood of mortality as percentage ${ }^{[19]}$ All the patients were followed during the entire duration of their hospital stay, and the outcome was recorded as mortality or discharge. Patients were divided into two groups based on 6-h sepsis bundle component compliance (complete vs. incomplete). Those fulfilling all the components of 6-h sepsis bundle were taken as compliant while failure to fulfill even a single component rendered them noncompliant. Both groups (compliant vs. noncompliant) were compared with outcome being measured in terms of mortality or discharge, dose, and duration of inotropes used, length of hospital stay, lactate levels, and time taken for perfusion to improve.

\section{Statistical analysis}

Categorical variables were presented as number and percentage $(\%)$, and continuous variables were presented as mean \pm standard deviation and median. Normality of data was tested by Kolmogorov-Smirnov test. If the normality was rejected then nonparametric test was used.

Statistical tests were applied as follows:

Quantitative variables were compared using Unpaired $t$-test/Mann-Whitney test (when the data sets were not normally distributed) between the two groups and Kruskal-Wallis tests was used for comparison between two groups. Qualitative variables were correlated using Chi-square test. $P<0.05$ was considered statistically significant. The data were entered into MS Excel spreadsheet and analysis was done using IBM SPSS Statistics for windows, Version 21.0 (IBM Corp., Armonk, NY: USA).

\section{Results}

A total of 116 patients with a diagnosis of severe sepsis and septic shock were included during the study. Out of which $62.93 \%$ were males as compared to $37.07 \%$ females. Ninety patients $(77.59 \%)$ were compliant while $26(22.41 \%)$ were noncompliant with the $6-\mathrm{h}$ sepsis bundle. Of 90 patients, 40 died $(44.44 \%)$ in the compliant group as compared to 5 out of $26(19.23 \%)$ in the noncompliant group, and the difference in mortality was statistically significant $P=0.020$. No significant differences were found in the compliant and noncompliant groups regarding the age, dose, and duration of inotropes (dopamine/dobutamine/ adrenaline), total hospital stay and time taken for perfusion to improve [Table 1].

Based on the predicted mortality, patients were divided into three subgroups (predicted mortality $<30 \%, 30 \%-50 \%,>50 \%$ ). 
Table 1: Comparison of basic charecteristics between compliant and noncompliant groups

\begin{tabular}{|c|c|c|c|}
\hline & No & Yes & $P$ \\
\hline Age in months & & & 0.904 \\
\hline Sample size & 26 & 90 & \\
\hline Mean \pm Stdev & $31.54 \pm 46.01$ & $32.67 \pm 40.66$ & \\
\hline Median & 6.45 & 12 & \\
\hline Min-Max & $1.1-132$ & $1-144$ & \\
\hline Inter quartile Range & $2.070-48$ & $3.033-48$ & \\
\hline Dopamine $(\mu \mathrm{g} / \mathrm{kg} / \mathrm{min})$ dose & & & 0.194 \\
\hline Sample size & 12 & 55 & \\
\hline Mean \pm Stdev & $14.83 \pm 3.95$ & $16.33 \pm 4.18$ & \\
\hline Median & 14 & 18 & \\
\hline Min-Max & $8-20$ & $10-20$ & \\
\hline Inter quartile Range & 13-19 & $11-20$ & \\
\hline Dopamine $(\mu \mathrm{g} / \mathrm{kg} / \mathrm{min})$ duration in days & & & 0.692 \\
\hline Sample size & 12 & 55 & \\
\hline Mean \pm Stdev & $16.37 \pm 47.47$ & $2.92 \pm 2.5$ & \\
\hline Median & 3 & 3 & \\
\hline Min-Max & $0.21-167$ & $0.04-10$ & \\
\hline Inter quartile Range & $1-4.500$ & $1-4$ & \\
\hline Dobutamine $(\mu \mathrm{g} / \mathrm{kg} / \mathrm{min})$ dose & & & 0.143 \\
\hline Sample size & 7 & 16 & \\
\hline Mean \pm Stdev & $6.8 \pm 6.02$ & $10.75 \pm 3.34$ & \\
\hline Median & 10 & 10 & \\
\hline Min-Max & $0.5-14$ & $6-20$ & \\
\hline Inter quartile Range & $0.525-11.500$ & $10-11$ & \\
\hline Dobutamine $(\mu \mathrm{g} / \mathrm{kg} / \mathrm{min})$ duration in days & & & 0.74 \\
\hline Sample size & 7 & 16 & \\
\hline Mean \pm Stdev & $2.75 \pm 1.3$ & $3.08 \pm 2.44$ & \\
\hline Median & 3 & 3 & \\
\hline Min-Max & $0.25-4$ & $0.31-10$ & \\
\hline Inter quartile Range & $2.250-3.750$ & $1.210-4$ & \\
\hline Adrenaline $(\mu \mathrm{g} / \mathrm{kg} / \mathrm{min})$ dose & & & 0.798 \\
\hline Sample size & 3 & 38 & \\
\hline Mean \pm Stdev & $1.33 \pm 0.58$ & $1.2 \pm 0.87$ & \\
\hline Median & 1 & 1 & \\
\hline Min-Max & $1-2$ & $0.2-3$ & \\
\hline Inter quartile Range & $1-1.750$ & $0.500-2$ & \\
\hline Adrenaline $(\mu \mathrm{g} / \mathrm{kg} / \mathrm{min})$ duration & & & 0.921 \\
\hline Sample size & 3 & 38 & \\
\hline Mean \pm Stdev & $1.76 \pm 2.8$ & $1.66 \pm 1.63$ & \\
\hline Median & 0.21 & 1 & \\
\hline Min-Max & $0.08-5$ & $0.08-7$ & \\
\hline Inter quartile Range & $0.114-3.802$ & $0.500-3$ & \\
\hline Time taken for perfusion to improve in $\mathrm{h}$ & & & 0.577 \\
\hline Sample size & 11 & 46 & \\
\hline Mean \pm Stdev & $8.36 \pm 8.15$ & $6.84 \pm 8.09$ & \\
\hline Median & 6 & 4 & \\
\hline Min-Max & $1-24$ & $0.5-36$ & \\
\hline Inter quartile Range & $3-9.250$ & $2-7$ & \\
\hline Total hospital stay in days & & & 0.832 \\
\hline Sample size & 26 & 90 & \\
\hline Mean \pm Stdev & $7.91 \pm 5.66$ & $8.23 \pm 7.12$ & \\
\hline Median & 7 & 7 & \\
\hline Min-Max & $0.17-21$ & $0.17-39$ & \\
\hline Inter quartile Range & 4-11 & $4-10$ & \\
\hline
\end{tabular}




\begin{tabular}{|c|c|c|c|c|c|}
\hline \multirow{2}{*}{$\begin{array}{l}\text { Predicted mortality } \\
\text { Subgroup }\end{array}$} & \multirow[t]{2}{*}{ Outcome } & \multicolumn{2}{|c|}{ Sepsis bundle compliance } & & \multirow[t]{2}{*}{$P$} \\
\hline & & No & Yes & & \\
\hline \multirow[t]{3}{*}{ 1) $<30 \%$} & $\mathrm{D} / \mathrm{S}$ & $21(87.50 \%)$ & $44(80.00 \%)$ & $65(82.28 \%)$ & 0.533 \\
\hline & Died & $3(12.50 \%)$ & $11(20.00 \%)$ & $14(17.72 \%)$ & \\
\hline & Total & $24(100.00 \%)$ & $55(100.00 \%)$ & $79(100.00 \%)$ & \\
\hline \multirow[t]{3}{*}{ 2) $30-50 \%$} & $\mathrm{D} / \mathrm{S}$ & $0(0.00 \%)$ & $3(21.43 \%)$ & $3(21.43 \%)$ & - \\
\hline & Died & $0(0.00 \%)$ & $11(78.57 \%)$ & $11(78.57 \%)$ & \\
\hline & Total & $0(0.00 \%)$ & $14(100.00 \%)$ & $14(100.00 \%)$ & \\
\hline \multirow[t]{3}{*}{ 3) $>50 \%$} & $\mathrm{D} / \mathrm{S}$ & $0(0.00 \%)$ & $3(14.29 \%)$ & $3(13.04 \%)$ & 1 \\
\hline & Died & $2(100.00 \%)$ & $18(85.71 \%)$ & $20(86.96 \%)$ & \\
\hline & Total & $2(100.00 \%)$ & $21(100.00 \%)$ & $23(100.00 \%)$ & \\
\hline \multirow[t]{3}{*}{ Total } & $\mathrm{D} / \mathrm{S}$ & $21(80.77 \%)$ & $50(55.56 \%)$ & $71(61.21 \%)$ & 0.02 \\
\hline & Died & $5(19.23 \%)$ & $40(44.44 \%)$ & $45(38.79 \%)$ & \\
\hline & Total & $26(100.00 \%)$ & $90(100.00 \%)$ & $116(100.00 \%)$ & \\
\hline
\end{tabular}

In $>50 \%$ predicted mortality subgroup, 18 out of $21(85.71 \%)$ died in compliant group, while 2 out of $2(100 \%)$ mortality was observed in noncompliant group $(P=1)$. In $<30 \%$ predicted mortality subgroup $12.5 \%$ died in the noncompliant group as compared to $20 \%$ in the compliant group $(P=0.533)$. Although overall mortality was significantly higher in the compliant group (44.44\% vs. $19.23 \%, P=0.02)$, the difference failed to reach significance in any of the predicted mortality subgroups because of less number of patients available in the noncompliant group [Table 2].

The initial blood lactate levels (mean and Standard deviation) were significantly higher $(6.97 \pm 3.54$ vs. $2.59 \pm 2.39, P<0.001)$ in the compliant group and the remeasured lactate within $6 \mathrm{~h}$ were still higher in the compliant group $(3.34 \pm 2.97$ vs. $0.52 \pm 0.33, P<0.019$ ) [Table 3].

Blood lactate levels (mean and Standard deviation) at admission (9.26 \pm 3.54 vs. $4.08 \pm 1.99)$ and remeasured lactate after sepsis bundle intervention $(5.34 \pm 3.23$ vs. $1.59 \pm 1.19)$ were significantly higher in those who died as compared to the survivors, $P<0.0001$ [Table 4].

Higher lactate levels were observed to be related to higher predicted mortality by PIM-2 score. Patients with more than $50 \%$ predicted mortality in compliant group had higher initial (mean and Standard deviation, 10.27 \pm 3.51 ) as well as post sepsis bundle intervention lactates (mean and Standard deviation, $6.28 \pm 3.65) P<0.0001$. In noncompliant group, the difference in initial and post-interventional lactate levels was not significant, $P=0.206$ [Table 5].

\section{Discussion}

In our study, we observed significantly high mortality among patients with high predicted mortality by PIM-2 score and high lactate levels despite absolute (100\%) compliance with the sepsis bundle. Irrespective of compliance, blood lactate levels were significantly higher in nonsurvivor group as compared to the survivor group, both before and after the intervention, $P<0.0001$.

\begin{tabular}{lccc}
\hline $\begin{array}{l}\text { Table 3: Blood lactate levels in compliant and } \\
\text { non-compliant groups }\end{array}$ & \\
\hline $\begin{array}{l}\text { Blood lactate levels } \\
\text { (mmol/l) }\end{array}$ & $\begin{array}{c}\text { No } \\
\text { Compliance }\end{array}$ & Compliance & $P$ \\
\hline Initial lactate & & & \\
Sample size & 18 & 90 & \\
Mean \pm Stdev & $2.59 \pm 2.39$ & $6.97 \pm 3.54$ & \\
Median & 2.1 & 5.8 & \\
Min-Max & $0.12-10.2$ & $2.7-18.5$ & \\
Inter quartile Range & $1.300-3.970$ & $3.900-8.890$ & \\
Remeasured lactate & & & 0.019 \\
Sample size & 3 & 81 & \\
Mean \pm Stdev & $0.52 \pm 0.33$ & $3.34 \pm 2.97$ & \\
Median & 0.38 & 2.3 & \\
Min-Max & $0.28-0.9$ & $0.15-13.8$ & \\
Inter quartile Range & $0.305-0.770$ & $1.350-4.500$ & \\
\hline
\end{tabular}

Table 4: Relationship of Blood lactate levels with outcome

\begin{tabular}{lccc}
\hline & D/S & Died & $\boldsymbol{P}$ \\
\hline Initial blood lactate & & & $<.0001$ \\
levels (mmol/l) & & & \\
Sample size & 63 & 45 & \\
Mean \pm Stdev & $4.08 \pm 1.99$ & $9.26 \pm 3.54$ & \\
Median & 3.9 & 8.89 & \\
Min-Max & $0.12-10$ & $2.3-18.5$ & \\
Inter quartile Range & $3.253-4.760$ & $7.758-12.288$ & \\
Remeasure lactate if & & & $<.0001$ \\
initially elevated & & & \\
Sample size & 47 & 37 & \\
Mean \pm Stdev & $1.59 \pm 1.15$ & $5.34 \pm 3.23$ & \\
Median & 1.5 & 4.5 & \\
Min-Max & $0.15-4.8$ & $1.1-13.8$ & \\
Inter quartile Range & $0.473-2.200$ & $2.800-6.900$ & \\
\hline
\end{tabular}

Phua et al., Samransamruajkit et al. and Rhodes et al. observed that adherence with 6 -h sepsis bundle was significantly associated with a decrease in mortality which is dissimilar to our study. ${ }^{[20-22]}$ In the study by Phua et al., it 


\begin{tabular}{|c|c|c|c|c|c|c|c|}
\hline \multicolumn{8}{|c|}{ Predicted Mortality (\%) } \\
\hline \multirow{2}{*}{$\begin{array}{l}\text { Blood lactate } \\
\text { levels (mmol/l) }\end{array}$} & \multicolumn{3}{|c|}{ Non-compliant patients } & \multicolumn{4}{|c|}{ Compliant patients } \\
\hline & $<30 \%$ & $>50 \%$ & $P$ & $<30 \%$ & $30 \%-50 \%$ & $>50 \%$ & $P$ \\
\hline Initial lactate & & & 0.206 & & & & $<.0001$ \\
\hline Sample size & 16 & 2 & & 55 & 14 & 21 & \\
\hline Mean \pm Stdev & $2.46 \pm 2.46$ & $3.65 \pm 1.91$ & & $5.42 \pm 2.56$ & $8.11 \pm 3.25$ & $10.27 \pm 3.51$ & \\
\hline Median & 2 & 3.65 & & 3.98 & 8.53 & 9.8 & \\
\hline Min-Max & $0.12-10.2$ & 2.3-5 & & $2.7-13.8$ & $3.99-13$ & $3.98-18.5$ & \\
\hline Inter quartile Range & $0.775-3.535$ & $2.300-5.000$ & & $3.800-7.050$ & $4.600-10.500$ & $8.575-12.475$ & \\
\hline Remeasured lactate & & & - & & & & $<.0001$ \\
\hline Sample size & 3 & 0 & & 48 & 14 & 19 & \\
\hline Mean \pm Stdev & $0.52 \pm 0.33$ & $0 \pm 0$ & & $2.25 \pm 1.83$ & $3.1 \pm 2.55$ & $6.28 \pm 3.65$ & \\
\hline Median & 0.38 & 0 & & 2.05 & 2.55 & 5.5 & \\
\hline Min-Max & $0.28-0.9$ & $0-0$ & & $0.15-8.8$ & $0.23-10.1$ & $1.7-13.8$ & \\
\hline Inter quartile Range & $0.305-0.770$ & & & $0.970-2.900$ & $1.700-3.500$ & $3.625-8.175$ & \\
\hline
\end{tabular}

was observed that compliance with individual elements of $6 \mathrm{~h}$ sepsis bundle was associated with decreased mortality. ${ }^{[20]}$ However, in contrast to our study, there was no significant difference in lactates $(P=0.17)$ among the survivor and nonsurvivor groups and Acute Physiology and Chronic Health Evaluation-II (APACHE-II) score was higher in the nonsurvivors $(P<0.001)$ which may account for more severity and hence high mortality in the noncompliant group.

Samransamruajkit et al. and IMPress study by Rhodes et al., ${ }^{[21,22]}$ observed that compliance with sepsis bundle $(70 \%$ and $36 \%$, respectively) was associated with decreased mortality. A single study in pediatric age group by Samransamruajkit et al., ${ }^{[21]}$ observed that implementation of sepsis bundle (two-time frames 2007-2009 and 2010-2011, before and after implementation of sepsis bundle) is associated with a reduction in mortality $(P=0.003)$ which is dissimilar to our study. In their study, there was not much difference in mortality prediction by PRISM-III score in pre- and post-sepsis bundle implementation whereas in our study the mortality was related to PIM-2 score mortality prediction and high lactates, irrespective of compliance. In IMPress study, ${ }^{[2]}$ the baseline lactates and illness severity scores, i.e., SOFA and APACHE-II were similar in both compliant and noncompliant groups, whereas in our study those who died had a higher baseline as well as postinterventional lactates and high predicted mortality by PIM-2 score.

Similar to our study, Peake SL et al., ${ }^{[23]}$ also observed in a randomized control trial including patients in early septic shock that 90 -day mortality was $18.6 \%$ in the compliant group as compared to $18.8 \%$ in the noncompliant group $(P=0.90)$. There were also no significant differences in 28 days or in-hospital mortality, duration of organ support, or length of hospital stay. The authors postulated that it is possible that this reduced risk of death in noncompliant group may be because of low rates of chronic disease and better functional status, as evidenced by the low proportion of nursing home residents before randomization.
Coba et al.,${ }^{[24]}$ observed that there was no significant difference in mortality among compliant and noncompliant groups after implementation of $6 \mathrm{~h}$ sepsis bundle (43.8\% vs. $47.8 \%$, $P>0.05)$. This may be attributed to high severity of illness reflected by high baseline APACHE-II scores, SOFA scores, and predicted mortality $(P<0.01)$ in the compliant group as compared to noncompliant group, which is similar to our study.

In our study, the blood lactate levels were also significantly higher in the compliant group as compared to the noncompliant group both before $(6.97 \pm 3.54$ vs. $2.59 \pm 2.39, P=0.0001)$ and after intervention $(3.34 \pm 2.97$ vs. $0.52 \pm 0.33, P=0.019)$ and high blood lactate levels were found to be significantly related to higher mortality which is similar to other studies. ${ }^{[25,26]}$

Despite a high compliance to $6 \mathrm{~h}$ sepsis bundle $(77.59 \%$ patients fulfilling all the elements of sepsis bundle) in our study, mortality was not affected. This difference in findings may be attributed to the high predicted mortality at admission and high pre- and post-intervention lactates irrespective of compliance.

No consensus exists among clinicians regarding optimal hemodynamic monitoring and till date no method has been proven to be superior. Usual care, nowadays, includes early fluid resuscitation and antibiotic administration; certainly, this reflects the impact of broad-based implementation of SSC guidelines and bundles. If this continues to define "usual care," then perhaps it is no longer necessary to mandate specific protocols for resuscitation, as it appears that standard sepsis management has evolved to be consistent with published protocols. ${ }^{[27]}$

\section{Conclusion}

In pediatric patients with severe sepsis and septic shock outcome is related to the severity of illness and lactate levels at the time of admission, irrespective of absolute adherence to $6 \mathrm{~h}$ sepsis bundle in our study. 
The limitation of our study was that the noncompliant group had less number of patients so that the difference in the outcome of compliant versus noncompliant in different predicted mortality subgroups (PIM-2 score $<30 \%, 30 \%-50 \%,>50 \%$ ) failed to reach significance.

As ours is a tertiary level health-care center, we receive patients from peripheral units with high predicted mortality due to delay in timely referral so that it is difficult to evaluate the reduction in mortality by sepsis bundle which is most effective when applied in early hours of the evolution of sepsis.

\section{Financial support and sponsorship}

Nil.

\section{Conflicts of interest}

There are no conflicts of interest.

\section{RefERENCES}

1. Angus DC, Linde-Zwirble WT, Lidicker J, Clermont G, Carcillo J, Pinsky MR, et al. Epidemiology of severe sepsis in the united states: Analysis of incidence, outcome, and associated costs of care. Crit Care Med 2001;29:1303-10.

2. Dellinger RP. Cardiovascular management of septic shock. Crit Care Med 2003;31:946-55.

3. Martin GS, Mannino DM, Eaton S, Moss M. The epidemiology of sepsis in the United States from 1979 through 2000. N Engl J Med 2003;348:1546-54.

4. Linde-Zwirble WT, Angus DC. Severe sepsis epidemiology: Sampling, selection, and society. Crit Care 2004;8:222-6.

5. Dombrovskiy VY, Martin AA, Sunderram J, Paz HL. Rapid increase in hospitalization and mortality rates for severe sepsis in the United States: A trend analysis from 1993 to 2003. Crit Care Med 2007;35:1244-50.

6. Kissoon N, Argent A, Devictor D, Madden MA, Singhi S, van der Voort E, et al. World federation of pediatric intensive and critical care societies-its global agenda. Pediatr Crit Care Med 2009;10:597-600.

7. Dellinger RP, Levy MM, Rhodes A, Annane D, Gerlach H, Opal SM, et al. Surviving sepsis campaign: International guidelines for management of severe sepsis and septic shock: 2012. Crit Care Med 2013;41:580-637.

8. Dellinger RP, Carlet JM, Masur H, Gerlach H, Calandra T, Cohen J, et al. Surviving sepsis campaign guidelines for management of severe sepsis and septic shock. Crit Care Med 2004;32:858-73.

9. Levy MM, Pronovost PJ, Dellinger RP, Townsend S, Resar RK, Clemmer TP, et al. Sepsis change bundles: Converting guidelines into meaningful change in behavior and clinical outcome. Crit Care Med 2004;32:S595-7.

10. Dellinger RP, Vincent JL. The surviving sepsis campaign sepsis change bundles and clinical practice. Crit Care 2005;9:653-4.

11. Gao F, Melody T, Daniels DF, Giles S, Fox S. The impact of compliance with 6-hour and 24-hour sepsis bundles on hospital mortality in patients with severe sepsis: A prospective observational study. Crit Care 2005;9:R764-70.
12. Castellanos-Ortega A, Suberviola B, García-Astudillo LA, Holanda MS, Ortiz F, Llorca J, et al. Impact of the surviving sepsis campaign protocols on hospital length of stay and mortality in septic shock patients: Results of a three-year follow-up quasi-experimental study. Crit Care Med 2010;38:1036-43.

13. Noritomi DT, Ranzani OT, Monteiro MB, Ferreira EM, Santos SR, Leibel $\mathrm{F}$, et al. Implementation of a multifaceted sepsis education program in an emerging country setting: Clinical outcomes and cost-effectiveness in a long-term follow-up study. Intensive Care Med 2014;40:182-91.

14. Levy MM, Rhodes A, Phillips GS, Townsend SR, Schorr CA, Beale R, et al. Surviving sepsis campaign: Association between performance metrics and outcomes in a 7.5-year study. Crit Care Med 2015;43:3-12.

15. Damiani E, Donati A, Serafini G, Rinaldi L, Adrario E, Pelaia P, et al. Effect of performance improvement programs on compliance with sepsis bundles and mortality: A systematic review and meta-analysis of observational studies. PLoS One 2015;10:e0125827.

16. Nguyen HB, Corbett SW, Steele R, Banta J, Clark RT, Hayes SR, et al. Implementation of a bundle of quality indicators for the early management of severe sepsis and septic shock is associated with decreased mortality. Crit Care Med 2007;35:1105-12.

17. Girardis M, Rinaldi L, Donno L, Marietta M, Codeluppi M, Marchegiano P, et al. Effects on management and outcome of severe sepsis and septic shock patients admitted to the intensive care unit after implementation of a sepsis program: A pilot study. Crit Care 2009;13:R143.

18. Hartman ME, Linde-Zwirble WT, Angus DC, Watson RS. Trends in the epidemiology of pediatric severe sepsis. Pediatr Crit Care Med 2013;14:686-93.

19. Available from: https://www.openpediatrics.org/assests/calculator/ pediatric-index-mortality-2. [Last accsessed 2018 Mar 25].

20. Phua J, Koh Y, Du B, Tang YQ, Divatia JV, Tan CC, et al. Management of severe sepsis in patients admitted to Asian intensive care units: Prospective cohort study. BMJ 2011;342:d3245.

21. Samransamruajkit R, Uppala R, Pongsanon K, Deelodejanawong J, Sritippayawan S, Prapphal N, et al. Clinical outcomes after utilizing surviving sepsis campaign in children with septic shock and prognostic value of initial plasma NT-proBNP. Indian J Crit Care Med 2014;18:70-6.

22. Rhodes A, Phillips G, Beale R, Cecconi M, Chiche JD, De Backer D, et al. The surviving sepsis campaign bundles and outcome: Results from the international multicentre prevalence study on sepsis (the IMPress study). Intensive Care Med 2015;41:1620-8.

23. ARISE Investigators; ANZICS Clinical Trials Group, Peake SL, Delaney A, Bailey M, Bellomo R, Cameron PA, et al. Goal-directed resuscitation for patients with early septic shock. N Engl J Med 2014;371:1496-506.

24. Coba V, Whitmill M, Mooney R, Horst HM, Brandt MM, Digiovine B, et al. Resuscitation bundle compliance in severe sepsis and septic shock: Improves survival, is better late than never. J Intensive Care Med 2011;26:304-13.

25. Bakker J, Gris P, Coffernils M, Kahn RJ, Vincent JL. Serial blood lactate levels can predict the development of multiple organ failure following septic shock. Am J Surg 1996;171:221-6.

26. Munde A, Kumar N, Beri RS, Puliyel JM. Lactate clearance as a marker of mortality in pediatric intensive care unit. Indian Pediatr 2014;51:565-7.

27. Levy MM. Early goal-directed therapy: What do we do now? Crit Care 2014; 18:705. 